\title{
ÉRASE UNA VEZ GABRIEL GARCÍA MÁRQUEZ, EL AHOGADO MÁS HERMOSO DEL MUNDO
}

\author{
No te hice ni celestial ni eternal, \\ Ni mortal ni inmortal, con el fin de \\ Que fueras libre y soberano artífice \\ de ti mismo, de acuerdo con tu designio.
}

PICO DELLA MIRANDOLA

\section{Introducción}

Márquez nos ha devuelto ese entrañable arte de contar cuentos que casi habíamos olvidado. Un ahogado, el más hermoso del mundo, el más bello y grande del mundo, nos recuerda la importancia de un cuento, de una historia susceptible de ser verídica. Su devenir en el cuento de Márquez nos pone en contacto con una realidad que es capaz de cambiar hacia lo inesperado y maravilloso, hacia lo fantástico y mágico, hacia lo realmente irreal de la realidad. Y es que nuestra falta de memoria nos está deshumanizando. Quizás porque ya no nos creemos nada; porque todos nos hemos vuelto tan hedonistas que olvidamos la esencia, y se nos vuelve la mirada estrábica ante una realidad que se muestra impermeable ante nuestros ojos. Y por eso mismo un día llega don Gabriel y nos recuerda cómo es todo aquello a lo que estamos dando la espalda, y nos recuenta la realidad a su manera, como los cuentos desde la lumbre, y como niños ávidos de nuevas experiencias y vivencias nos quedamos boquiabiertos con nuestro cuentacuentos tiresiano, que no ciego. Despertando de nuestras abulias vitales volvemos a entusiasmarnos con un cuento tan realmente mágico como la vida misma.

Cuentos, cuentos, cuentos ... porque la vida es un puro fluir de cuentos que caminan, vuelan, nadan, se ahogan entre mares de muy sugerentes apreciaciones empíricas, se pierden, se esconden ... pero sobre todo ponen en peligro a esa aparente realidad unívoca que nos enseñan a aprehender desde que tenemos uso de razón, olvidando otros tipos de acercamientos hacia una realidad que nada tiene que ver con lo singular y lo único.

La realidad no es susceptible de ser atrapada entre la tiranía de lo "uno" porque es múltiple, porque es como una sinfonía donde cada uno de los instrumentos tienen un lugar único e irremplazable.

La realidad es indefinible porque intentar atraparla entre palabras de un solo significante es asesinarla, es acabar con su esencia polifónica. Por eso necesitamos de los cuentos para acercarnos de una manera consecuente con la realidad, para llegar con fidelidad y con auténticas ansias de conocimiento verdadero. Son los cuentos los que nos enseñan a despertar de la equívoca prepotencia de una realidad material que exalta la razón sobre los demás aspectos vitales. 
Don Gabriel nos ha devuelto una parte de nuestras realidades al redimirnos de la monotonía con su recuperado arte de contar.

También para Ricardo Gullón don Gabriel se muestra como un genuino cuentacuentos que nada tiene que ver con sus coetáneos. Para Gullón "lo excepcional de Gabriel García Márquez en un panorama novelístico como el del presente, preocupados con la técnica, consiste en no sentir esa preocupación, sino la de imaginar como quien respira, expresando del modo más directo y más preciso lo que la imaginación le dicta".'

\section{Irrupción de lo fantástico como elemento de activación de realidad: la concienciación}

La entrada del elemento fantástico en la vida diaria del pueblo protagonista pone de relieve la falta de conciencia del pueblo tanto individualmente como colectivo. El elemento mágico no hace sino poner de manifiesto la escisión existente entre los tres colectivos (niños, mujeres y hombres) que se hallan en el pueblo. El disloque de las tres diferentes perspectivas que cada uno de los colectivos evoca a partir de la aparición del ahogado nos muestra un pueblo anónimo y fragmentado, subordinado a la esclerosis de la rutina y de lo predecible. El acontecimiento fantástico de la llegada del ahogado al pueblo va a suponer la ruptura de todo esto. El ahogado fabuloso les va a dar la oportunidad de reafirmarse y unirse, ofreciendo al pueblo instrumentos colectivos de concienciación que le van a capacitar para vencer esa sumisión aparentemente fosilizada a la rutina y a la división que había acuciado al pueblo del ahogado.

Pero también sabían que todo sería diferente desde entonces, que sus casas iban a tener las puertas más anchas, los techos más altos, los pisos más firmes, para que el recuerdo de Esteban pudiera andar por todas partes sin tropezar con los travesaños, y que nadie se atreviera a susurrar en el futuro ya murió el bobo grande, qué lástima, ya murió el tonto hermoso, porque ellos iban a pintar las fachadas de colores alegres para eternizar la memoria de Esteban (...). ${ }^{2}$

Paradójicamente, será el elemento fantástico (personaje creado y bautizado por el propio pueblo) quien dará identidad y conciencia al pueblo anónimo. El pueblo se identificará con Esteban, y Esteban generará la identidad y la singularidad al pueblo.

(...) y el capitán dijera en catorce idiomas, miren allá, donde el viento está ahora tan manso que se queda a dormir debajo de las camas, allá, donde el sol brilla tanto que no saben hacia dónde girar los girasoles, sí, allá, es el pueblo de Esteban. ${ }^{3}$

El ahogado más hermoso del mundo irrumpirá en la cotidianeidad del pueblo, romperá el orden fáctico establecido, producirá el asombro y la recuperación de la conciencia individual y colectiva, y después de destapar el auténtico problema de un pueblo enfermo de soledad, desaparecerá. Y es cuando el ahogado desaparece cuando realmente se produce el desvelamiento del verdadero eje de la acción. El final nos desvelará que no es la historia de Esteban, el ahogado más hermoso del mundo lo que don Gabriel escribió, sino que bajo esta aparente historia sencilla subyace la narración principal, es decir, el redescubrimiento de sí mismo del pueblo y su revitalización y unión posterior.

\footnotetext{
${ }_{1}^{1}$ Gullón, Ricardo, García Márquez o el olvidado arte de contar cuentos. Ed. Taurus, Madrid, 1970, p. 56.

${ }^{2} \mathrm{y}^{3}$ García Márquez, Gabriel, La increible y triste historia de la cándida Eréndira y de su abuela desalmada. Ed. Mondadori, Madrid, 1987, pp. 50-51.
} 
La gran contradicción que encierra este cuento es ver cómo el elemento fabuloso es el que crea la verdad, y cómo cuando la verdad se ha desvelado, y el pueblo ha adquirido su identidad por completo, es imprescindible que el elemento maravilloso desaparezca de nuevo. Porque para poseer a Esteban hay que dejarle completamente libre, ya que poseerle anclado al pueblo sería acabar con su naturaleza dinámica. La función principal de Esteban estriba en ser el elemento fantástico y maravilloso que renueva la realidad agotada del pueblo con su irrupción. Si Esteban quedara anclado al pueblo, perdería su carácter mágico y único, extinguiéndose el elemento sorpresa con el transcurrir de los días. $\mathrm{El}$ ahogado tiene que seguir vagando libre y sin ataduras para permitir al pueblo no someterse a un nuevo orden que pudiera venir definido por Esteban. El ahogado más hermoso del mundo reinventa al pueblo, y el pueblo ha de aprender ahora a seguir reinventándose para dar sentido a sus vidas sin la sumisión de Esteban, porque éste les ha otorgado la singularidad y capacidad de activación propias, sin dependencias externas de ningún tipo de orden establecido: "No tuvieron necesidad de mirarse los unos a los otros para darse cuenta de que ya no estaban completos, ni volverían a estarlos jamás". ${ }^{4}$

Esteban despertó la unidad y singularidad al pueblo protagonista, y llenó el vacío del que habían sido víctimas por culpa de la rutina tanto a los niños (convirtiéndose en un juguete fantástico capaz de dar rienda suelta a sus imaginaciones) como a las mujeres (encarnando un varón asombroso, príncipe de sus sueños alrededor del cual se proyectarán fantaseando y entreteniéndose con el adolescente juego de amar una imagen que no pertenece a la realidad empírica). Frente a este potencial creador e imaginativo que encontramos en estos dos colectivos, hayamos el grupo de los hombres que se manifiesta desde la aparición del ahogado de una forma existencialmente pragmática. Esa separación que planea en el cuento desde su inicio entre la potencialidad creadora de los niños y mujeres, y el pragmatismo cotidiano de los hombres culminará en una conjunción que tiene de nuevo como centro y soporte los funerales de Esteban.

Parece que finalmente, la pasividad y sumisión con la que se vivía la rutina y la dureza del medio que rodea al pueblo se convierte en una activación por parte del pueblo, que es capaz de revelarse contra el anonimato, y recrearse a sí mismo con su final toma de conciencia. Su reencuentro con su propia identidad hace que el pueblo de Esteban avance unido luchando contra la soledad del hombre del siglo XXI, retándola con este proyecto ideal comunitario que ha sido el funeral del ahogado más hermoso del mundo, y que les ha permitido reivindicar su propia existencia rompiendo con los ecos de sus propias soledades.

\section{Una mirada caleidoscópica de la realidad}

Con la técnica del realismo mágico, Márquez presenta una historia aparentemente lineal sobre un pueblo que se reinventa y toma conciencia de sí mismo a partir de un elemento ilusorio que toma contacto con la cotidianeidad del mundo narrado en forma de intrusión.

\footnotetext{
${ }^{4}$ García Márquez, Gabriel, La increible y triste historia de la cándida Eréndira y de su abuela desalmada. Ed. Mondadori, Madrid, 1987, p. 50.
} 
El espacio narrado se conoce a partir de la mirada de los agentes, y los agentes se nos van definiendo por su proyección en el narrar. El narrador, con cámara cinematográfica en mano, nos introduce en el escenario desde una panorámica del pueblo protagonista sobre el que no intervendrá salvo para presentarnos a los personajes. Una vez activado el primer plano, la acción, la intervención directa del narrador pasará a desdibujarse en un nuevo contador colectivo que, por medio de monólogos y diálogos de cuanto los personajes dicen y piensan, serán capaces de crear con el tono exaltado que adquieren los protagonistas al final de la historia una nueva voz (la del capitán del futuro) que seguirá contando la historia del pueblo de Esteban, revelándose el primer narrador a los límites espacio-temporales.

La multiplicación cubista del narrador y de los hechos narrados provee de base a la estructura. La proyección que del ahogado tenemos a partir de la palabra de los agentes permite caracterizar a los protagonistas mismos. El hecho de que el papel del narrador haya tomado - una vez introducidos los personajes - un papel virtual y subjetivo, hace que el narrador no tenga opción de subrayar un elemento en detrimento de otro. La simultaneidad de perspectivas tan dispares como puedan ser la del grupo de los niños, la del grupo de las mujeres o la del grupo de los hombres impide hacer una lectura lineal de una realidad unívoca. Esta mirada calidoscópica orquesta una sinfonía de perspectivas caracterizadoras del mundo narrado más o menos dispares, que establecen la realidad narrada a un nivel subjetivo en donde es la proyección de los protagonistas quienes definen la realidad.

Los agentes tienen como función básica observar, identificar, preguntarse, soñar, compadecerse, ilusionarse, desengañarse, indagar, descubrir, comprender, entusiasmarse, apasionarse ... hasta llegar finalmente a la culminación, que será la toma de conciencia de sí mismos tanto como individuos como colectivo. La anodina normalidad quedará trastocada por la aparición de una inusitada visita misteriosa y fantástica a la vez, que romperá con el orden lineal aceptado hasta el momento de la reveladora llegada del ahogado más hermoso del mundo, que traerá consigo la puesta en escena de un nuevo orden desligado de lo puramente empírico y fáctico, que vendrá definido por los protagonistas.

El lector se convierte de esta manera en un elemento activo que experimenta los mismos sentimientos de los protagonistas en esta dinámica que una vez reactivada va transformándose paso a paso en interés, pasión, compasión, para terminar en un amor profundo en Esteban, el ya nominado ahogado más hermoso del mundo.

\section{Conclusión}

Así, don Gabriel se nos aparece en sus cuentos como un árbitro de una realidad propia en la cual se borran del modo más sencillo y tolerable las fronteras entre lo real y lo fantástico. Para la voz del narrador de sus historias fabulosas - y de toda su obra en general - no hay diferencia entre lo verosímil y lo inverosímil; sólo le preocupa su función de cuentacuentos donde todo se cuenta y recuenta sin importarle si habla de niños o de muertos, asociando sin pestañear lo fantasma con lo tangible. Su imperturbabilidad se revela en lo inalterable del tono, siempre al mismo nivel, sin fluctuaciones ni variantes. 
Absolutamente todo, desde los sucesos más cotidianos y anodinos hasta los acontecimientos más fantásticos y fabulosos tienen cabida en la realidad. Todo es susceptible de ser verdad o de ser mentira en nuestra realidad, que al ser recontada por don Gabriel queda enriquecida por millones de planos que se superponen y que intentan recomponer el gran espejo del mundo. $Y$ este gran espejo del mundo componen un microcosmos en la obra del escritor, que se constituye como "un sistema retroactivo, prospectivo e introspectivo que tiene la necesidad ficticia de estructurarse y de renovarse de ficción a ficción, sin cortar nunca totalmente con ninguno de sus estadios anteriores".

Reconocemos en su obra un paradójico doble movimiento: uno de avance, de creación, de generación, de indagación de lo que queda por ser descubierto, por ser desvelado, y otro de retroceso, de vuelta a lo ya descubierto, a lo ya existente, a lo familiar, a lo ya conocido. $Y$ en este doble movimiento, hay una clara intención integradora de fusión entre ambos movimientos, entre ambas actitudes. Lo pasado y lo futuro tienen que conjugarse en un mismo plano que no entiende de coordenadas de espacio o de tiempo. No existen incoherencias ni imposibles, sino una perfecta polifonía de planos que no entienden de límites. ${ }^{6}$ Parece que este microcosmos personal de Márquez no hace sino referirnos una y otra vez a un mismo núcleo alrededor del cual se concentra y fluctúa toda su obra: el sentimiento de soledad del hombre del siglo XXI.

\section{Bibliografía selecta}

Aronne-Amestoy, Lida, Utopía, paraíso e historia. Ed. Benjamins, Amsterdam, 1986.

De Albornoz, Aurora, "Un cuento de Gabriel García Márquez: El ahogado más hermoso del mundo" en El comentario de textos, 2. Ed. Castalia, Madrid, 1974.

Bal, M., Teoría de la narrativa, Ed. Cátedra, Madrid, 1987.

García Márquez, Gabriel, Cien años de soledad. Ed. Espasa Calpe, Madrid, 1985.

-. La hojarasca. Ed. Plaza \& Janés, Barcelona, 1979.

-. La increíble y triste historia de la cándida Eréndira y de su abuela desalmada. Ed. Mondadori, Madrid, 1987.

-. Los funerales de Mamá Grande. Ed. Plaza \& Janés, Barcelona, 1998.

Gullón, Ricardo, García Márquez o el olvidado arte de contar cuentos. Ed. Taurus, Madrid, 1970. Vargas Llosa, Mario, García Márquez: Historia de un deicidio. Ed. Barral, Barcelona, 1971.

\footnotetext{
5 Vargas Llosa, Mario, García Márquez: Historia de un deicidio. Ed. Barral, Barcelona, 1971, p. 98.

6 Así, en El ahogado más hermoso del mundo reconocemos algunos de los muchos de los elementos intertextuales que conforman el microcosmos personal de la obra de don Gabriel (La llegada a un pueblo de un ser u objeto extraordinario que irrumpe y transforma el entorno donde hace aparición lo encontramos en El mar del tiempo perdido (encarnado en el señor Herbert) y Cien años de soledad; el cuento que me ocupa gira en torno a una muerta y sus funerales, como queda bien latente en las obras de La hojarasca y Los funerales de Mamá Grande; Sir Walter Raleigh es un corsario que aparece mencionado al final de El ahogado más hermoso del mundo al igual que también aparece nombrado en Cien años de soledad; al igual que en El mar del tiempo perdido, los acontecimientos tienen como escenario un pequeño pueblo marítimo donde conviven pocos habitantes que comparten la misma vida rutinaria y monotona que aparece en El ahogado más hermoso del mundo).
} 


\section{NEKOČ JE BIL GABRIEL GARCÍA MÁRQUEZ NAЛEPŠI UTOPLJENEC NA SVETU}

Avtorica članka na podlagi kratke zgodbe Gabriela Garcie Márqueza »Najlepši utopljenec na svetu « želi pokazati, kako izbruh magičnega in fantastičnega v njegovem pripovedništvu pokaže razkol normalnega in kako ta vdor spodbudi ozaveščenje tako na individualni kot na kolektivni ravni. Pisatelj uporabi fantastični element kot obliko provokacije; ko se prelom in ozaveščenje normalnosti vzpostavita, ju spet skrije v obliki sprave $\mathrm{z}$ realnostjo. $\mathrm{V}$ obravnavani kratki zgodbi pojavitev najlepšega utopljenca na svetu spodbudi vaščane $\mathrm{k}$ skupnemu boju proti osamljenosti človeka $\mathrm{v} 21$. stoletju $\mathrm{z}$ idealnim kolektivnim projektom, kot je pogreb utopljenca, ki jim omogoči, da prikličejo lastno eksistenco in pretrgajo odmeve njihovih samot. 